Preprints of the

Max Planck Institute for

Research on Collective Goods

Bonn 2011/9

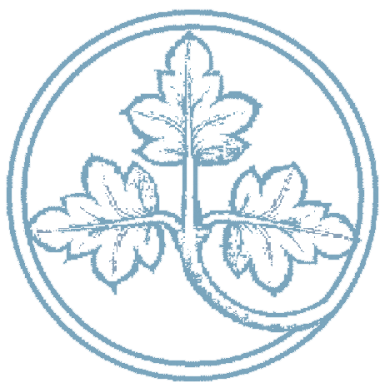

Using Forward Contracts to Reduce Regulatory Capture

Felix Höffler

Sebastian Kranz

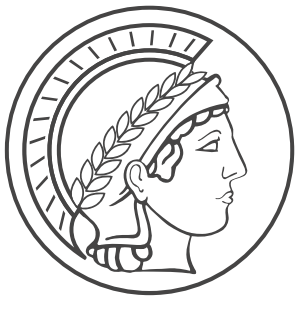




\section{Using Forward Contracts to Reduce Regulatory Capture}

Felix Höffler / Sebastian Kranz

May 2011 


\title{
Using Forward Contracts to Reduce Regulatory Capture
}

\author{
Felix Höffler ${ }^{1}$ and Sebastian Kranz ${ }^{2}$
}

April 2011

\begin{abstract}
A fully unbundled, regulated network firm of unknown efficiency level can undertake unobservable effort to increase the likelihood of low downstream prices, e.g., by facilitating downstream competition. To incentivize such effort, the regulator can use an incentive scheme paying transfers to the firm contingent on realized downstream prices. Alternatively, the regulator can propose to the firm to sell the following forward contracts: the firm pays the downstream price to the owners of a contract, but receives the expected value of the contracts when selling them to a competitive financial market. We compare the two regulatory tools with respect to regulatory capture: if the regulator can be bribed to suppress information on the underlying state of the world (the basic probability of high downstream prices, or the type of the firm), optimal regulation uses forward contracts only.
\end{abstract}

Keywords: Incentive regulation, regulatory capture, virtual power plants JEL-Classification: L43, L51, K23, L94

\footnotetext{
${ }^{1}$ Institute for Energy Economics, University of Cologne, and Max Planck Institute for Research on Collective Goods, Bonn.

${ }^{2}$ Department of Economics, University of Bonn, Adenauerallee 24-26, 53113 Bonn, Germany. skranz@unibonn.de. I thank the Deutsche Forschungsgemeinschaft for financial support through SFB/TR 15 .

We are grateful to Christoph Engel, Olga Gorelkina and Yoan Hermstrüwer for helpful comments.
} 


\section{Introduction}

In many liberalized electricity markets, regulation exclusively focuses on the network as a monopolistic bottleneck. To achieve a satisfactory market outcome, in particular, to avoid excessive prices, regulation concentrates on ensuring access to the network at regulated tariffs. However, the scope of activities of network operators goes far beyond providing a well defined access product at regulated terms. In particular operators of the high voltage grid influence the wholesale electricity price (and thereby also the final market price) by a multitude of activities. Decisions on network operations, market design, or investments - they all affect the level of competition, the system cost, and - under the European Emission Trading System (ETS) - they have a huge impact on the CO2 price, which has become a substantial part of the wholesale price. $^{3}$

The standard tools of regulatory practice, in particular caps on the network firm's prices or revenues, are well suited to provide incentives for a cost efficient provision of a well defined access product; but they are less suitable to steer these other aforementioned activities of the network firm. However, in principle, incentives for these activities which tend to reduce the wholesale electricity price are easy to provide. Regulators just need to specify transfers to the firm which are decreasing in the wholesale price. ${ }^{4}$

Unfortunately, such a scheme is quite vulnerable to regulatory capture. While network operators have a significant impact on the market prices, these prices are also affected by many other factors, like fuel costs or demand shocks, leading to substantial uncertainty and variability of future prices. Imagine the regulation wants to implement a transfer scheme that to ensure participation of the firm - leads to zero expected transfers. The expected transfers will then strongly depend on the regulator's assessment of future prices. If the regulator overestimates expected future prices, the network operator will gain money on average. Thus, a network operator might benefit a lot from influencing the regulator's assessment about expected future prices.

In this paper, we analyze an alternative and simple regulatory tool that can provide the same incentives but is less vulnerable against regulatory capture. We suggest that the regulator can propose to the network operator to auction off a fixed quantity of forward contracts,

\footnotetext{
${ }^{3}$ We provide detailed examples for these mechanisms in the next section.

${ }^{4}$ An early proposal of aligning a monopolist's incentives with transfers was given by Loeb and Magat (1979). They suggest transfers that match the change in consumer surplus and thereby induce optimal pricing by a single good monopolist. Generally, transfers are a key element in most literature on mechanism design and optimal regulation.
} 
which entitles their holder to future payments from the network operator that are increasing in future wholesale prices. From an incentive perspective it does not matter whether the network operator benefits from low wholesale prices because they reduce payments to the buyers of the forward contracts or because they increase transfers from the regulator. Yet the expected net-transfers, i.e. the difference between auction revenues and discounted expected future payments by the network firm, depend now on the financial investors' assessment of future prices.

Similar to exaggerated regulatory transfers, the network operator benefits if financial investors overestimate expected future prices and therefore make higher bids in the auction. But if financial investors bid too much, they lose exactly the same amount of money as the network operator gains. This makes any bribes unprofitable that have to compensate financial investors for resulting losses. In contrast to a regulator who specifies transfers that are to be paid by consumers or tax payers, financial investors who buy forward contracts have financial stakes that are in total as large as the network operator's.

For a formal analysis of these ideas, we build on the framework proposed by Laffont and Tirole (1991), with a benevolent legislator, a corruptible regulator who may receive and report information about the state of the world, and a network firm undertaking a hidden action. In this framework, a regulation based solely on outcome contingent transfers will leave rents to the firm to avoid that the regulator is bribed to suppress information.

We first study forward contracts assuming risk-neutral, competitive financial investors that have the same information as the network firm and the regulator. A regulation using forward contracts can then implement the first best outcome that avoids giving rents to the network operator. Forward contracts allow in this case a regulation that is completely independent of the assessment of the regulator and thereby robust against bribes.

The superiority of forward contracts is less straightforward if the network operator has private information about its type, which is revealed to the regulator and to the financial market with some probability only. While the first best outcome can typically not be achieved, using a combination of forward contracts and transfers generally leads to a welfare increase compared to a regulation relying on outcome contingent transfers only. Surprisingly, the optimal regulation with forward contracts will not only leave an information rent to the efficient type, but also yields a rent for the inefficient type of network operator. However, rents are unambiguously lower with forward contracts, compared to using outcome contingent transfers only.

The main results are derived under the assumption of symmetric information between the 
financial market and the regulator, but shown to be robust to either superior information by the regulator or the financial markets. When auctions are costly due to imperfections in financial markets, relying on forward contracts will not always be optimal. An analysis of comparative statics shows that forward contracts are generally more beneficial if a large part of uncertainty about future wholesale prices arises from external factors rather than internal factors privately known to the network operator.

Forward contracts have been intensively discussed in the literature, mainly with a focus on forward contracting by firms producing a final product. Under Cournot competition without collusion, forward contracting tends to reduce the final product's price (Bushnell (2007), Allaz and Vila (1993)), while under Bertrand competition (Mahenc and Salanie (2004)) or collusive play in dynamic Cournot competition (Liski and Montero (2006)) forward contracts tend to increase the price. Our analysis differs from this discussion since, (i) we look at contracting by an intermediary (the network operator), (ii) the amount of contracts is not a choice variable of the firms, but imposed by the regulator, and (iii) our focus is on the issue of regulatory capture.

Several papers have analyzed forward contracting arrangements that are imposed by a regulator in the energy industry (e.g. de Frutos and Fabra (2009), Fabra and Toro (2005), or, for "virtual power plants", Schultz (2009)). Also these papers' contribution is to understand the impact of such contracts on the strategic interaction in the final product market, while we investigate the contracts being used to mitigate regulatory capture.

The positive theory of regulation has for a long time recognized and discussed the problem of regulatory capture (see Stigler (1971) and Peltzman (1976)). Levine and Forrence (1990) provide an overview of the different perspectives on regulation, the "public interest" view and the "capture" view. Dal Bó (2006) discusses more recent literature and also includes empirical results on regulatory capture.

The analysis of corruptible agents goes back to the three tier principal-supervisor-agent model proposed by Tirole (1986), which later was explicitly applied as a government-regulatorregulated firm model by Laffont and Tirole (1991) (and summarized in Laffont and Tirole (1993), Ch. 11). This literature usually focuses on the interaction of optimal regulation and incentive contracts between the legislator and the regulator, which influence the cost of bribes. Although we also use a three tier model, to focus our analysis on the role of forward contracts, we abstract from incentive contracts between legislator and regulator and make the simplifying assumption that the costs of bribes are exogenously given.

Finally, our paper is also related to Faure-Grimaud (2002). He focuses on the question how 
the use of stock price information in regulation might substitute information gathering by the regulator and can solve problems of a regulator to commit long term. While our focus is different (we look for solutions for the problem of regulatory capture, while he looks for solutions to the asymmetric information problem), the spirit of the papers is similar: The idea is to use the financial market as a third party to solve a contracting problem.

The remainder of the paper is organized as follows. Section two provides more information on the European electricity industry as the key application of our thoughts. Section three starts the basic analysis by investigating a pure moral hazard problem. Section four completes the basic analysis by additionally investigating adverse selection and provides the main result. Section five considers different informational assumptions, the case of transaction costs in auctions, and regulations that condition on the auction proceeds. Section six concludes.

\section{Application to the European electricity industry}

The leading application for our ideas is the European electricity industry, where in many member states (UK, Sweden, Netherlands, or parts of Germany) the network operators are fully vertically unbundled, i.e., the network firms are active neither upstream (generation), nor downstream (retail). In these industries, our model should be relevant since (i) network firms have a huge impact on wholesale prices, (ii) the regulatory system involves huge transfers to the firms such that regulatory capture might well be an issue, ${ }^{5}$ and (iii) forward contracts are traded in liquid financial markets, and some regulators have already used tools similar to the ones proposed in this paper.

There are at least three important transmission mechanisms for network operators to influence the wholesale price, and thereby, the final market price. First, the network operators' behavior affects the intensity of competition in the wholesale market. The most obvious transmission channel is the behavior towards new generators, in particular, how quickly they are hooked up to the grid, and at which costs. Even more important is the effect of the network operators' behavior with respect to establishing a uniform European market for electricity. At many European borders, networks are congested. Already small increases of capacity can significantly increase cross-border competition (Borenstein, Bushnell, and Stoft (2000)), but the network operators' incentives to work towards this aim are unclear. Under

\footnotetext{
${ }^{5}$ In November 2010, EU commissioner Guenther Oettinger proposed an energy strategy for Europe. For the high voltage electricity grids, investments were calculated to amount to 200 billion Euro, half of which will require public funding, according to Oettinger (EU Commission, $\operatorname{COM}(2010) 677$, p. 9.).
} 
the current regulation, operators have a choice whether to invest congestion revenues into network extensions or to use them to reduce national network fees. Only the former would increase cross-border competition, but some network operators consistently chose the latter. ${ }^{6}$ Second, market design choices and operational decisions have a similar effect. It is commonly agreed that cross-border market integration, so called market coupling, improves the market efficiency. Implementing such market coupling requires complex cooperations between different network operators and electricity exchanges. The level of cooperation is a choice variable of the network operator. Similar reasoning applies for operational choices. The amount of cross-border capacity actually available is not a mere technological parameter, but depends on the network operator's assessment of the need for network reserves required for network security. In either case it remains unclear (and it depends on the regulation) what the network firm's incentives are to choose the socially desired behavior.

Third, many investment decisions have a (long-term) influence on the wholesale market price. Certain types of investments are suitable to reduce the system cost. A prominent example is the so-called NorNed link between the Dutch and the Norwegian electricity system, build and operated by the two national grid companies. This allows to use cheap Dutch base load electricity in the night to fill Norwegian water reservoirs, which, in turn, can produce for daytime peak hours in the Netherlands. Another important aspect involves network investments that facilitate the usage of renewable energy sources. Currently, low emission generation is not located at the most effective places. For instance, Germany has the largest amount of photovoltaics in Europe, although obviously more favorable locations are available in the Mediterranean region. ${ }^{7}$ To use the most efficient location would reduce CO2-Emmission prices, and thereby the electricity wholesale price, which includes these emission costs, but would also require significant network investments.

All the examples mentioned have two properties in common. First, in all cases the network firm's behavior influences the market price of electricity. Second, although the outcome of the network firm's can be observed (e.g., that certain network connections are not build, or are build only with long delays), it is not clear how much effort the network firm has put forward (e.g., whether delays are subject to a lack of effort, or are due to other adverse circumstances).

\footnotetext{
${ }^{6}$ Between 2001 and 2005, German transmission system operators invested less than $10 \%$ of the congestion revenues to reduce congestion, see the speech of Neelie Kroes: A new energy policy fo a new era, Conference on European Energy Strategy, Lisbon, 30th October, 2006.

${ }^{7}$ See Fürsch, Golling, Nicolosi, Wissen, and Lindenberger (2010) for the cost reducing effects of a harmonization of support systems for renewable energy in Europe. This study, however, does explicitly neglect the additional network investments needed for such a harmonization.
} 
Under the current regulation, in none of the mentioned examples it is clear how the network firm could ever benefit from undertaking exactly the desired activities that reduce the wholesale prices since the current regulatory regime mainly relies on a cost plus regulation for network investments. Network firms can apply for "investment budgets" which are examined by the regulators and, if approved, allow for an increase of the network charges. Thus, all network users finance the network investments. ${ }^{8}$ It is well understood that cost plus regulation provides little incentives for cost efficient behavior. Furthermore, the incentive to apply for investment budgets is unclear in case of a regulated unbundled network operator. Obviously, large investments will be triggered if the mark-up (the "plus") in the cost-plus regulation is sufficiently large. This raises not only the concern how to provide incentives to implement the efficient projects, but also - due to the large transfers to the industry - the challenges arises how to ensure the independence of the regulatory decision making.

Our approach suggests to use information from financial markets for providing incentives for the network firm, and at the same time, taking care of the problem of regulatory capture. In most European countries, a liquid electricity exchange indeed exists, and forward contracts are already traded. Therefore there already exists expertise in electricity markets that might be able to also evaluate the forwards contracts that we propose.

In this context, it is interesting to note that the form of incentive regulation that conditions payments on realized market prices is not new to Europe. When the Spanish electricity market was liberalized, "Competition Transition Costs" where introduced, which essentially were transfers from the state to the firms which were decreasing in the electricity price, thereby providing incentives for price reducing actions. In 1998, these "Competition Transition Costs" payments amounted to Euro $633.5 \mathrm{mn}$. (Fabra and Toro (2005)). Another related competition policy instrument frequently used in merger cases are "virtual power plants". 9 The merging firms have to sell "virtual capacity", and buyers receive the right to buy electricity at a predefined $\bar{p}$ price. This is like forcing the merging firms to sell a call option with a strike price

\footnotetext{
${ }^{8}$ For instance, in the German energy regulation, an "investment budget" increases the so-called "long-term unavoidable cost" and thereby increases the revenue cap of the firm (see "Anreizregulierungsverordnung, $§ 11$ (2) no. 6"). Essentially, this means that all network users, not only those actually using the new infrastructure, have to pay higher access charges to the network operator.

Investment budgets are large. For instance, in 2010 German grid companies applied for 7.9 bn. Euro only for connecting off-shore windparks (of which $4.3 \mathrm{bn}$. Euro were approved, see Bundesnetzagentur, Tätigkeitsbericht Gas und Strom 2010, p. 26). In the UK, the regulator accepted an investment budget equivalent to almost half of the network's book value of assets ( $4.5 \mathrm{bn}$. Euro) for the period 2008-2012 (see Ofgem, Transmission Access Review, Ref. 175/08, p. 5 and p.8).

${ }^{9}$ For instance the merger between EdF and EnBW (EU Commission, Case COMP/M 1853), or between Nuon and Reliant (Dutch Competition Authority, Press Release 03-49 as of 11-27-2003).
} 
$\bar{p}$. The instrument that we propose can be seen as a mixture of the Spanish case and virtual power plants: The regulator forces the network operator to sell forwards where the network firm's obligations increase in the electricity wholesale price, but the network firm can keep the proceeds of the auction. In the following model, we want to analyze incentive effects of such an instrument in the presence of regulatory capture.

\section{A Model of Pure Moral Hazard}

\subsection{Optimal regulation without financial contracts}

To formulate our ideas, we restrict attention to a very stylized model of a network industry. A network operator ("firm") provides an essential input for a downstream market. The price in the downstream market (which, in our application, is the electricity wholesale price) is stochastic, but influenced by the firm. For simplicity, we assume that the downstream market price $p$ can take on only two values, $p \in\left\{p_{L}, p_{H}\right\}$, where $p_{L}<p_{H}$. The probability of a high price is:

$$
\operatorname{Pr}\left(p=p_{H}\right)=x+\eta(1-e)
$$

and the probability of a low price is $1-\operatorname{Pr}\left(p=p_{H}\right)$.

The network operator chooses between two unobservable effort levels $e \in\{0,1\}$ where high effort $e=1$ corresponds to costly actions that reduce the probability of a high downstream price. Effort costs are unobservable and equal to $c e$, with $c>0$. The parameter $\eta \geq 0$ measures how strongly the firm's effort decreases the probability of high prices.

The parameter $x$ denotes the baseline probability of high prices. It measures factors like expected demand conditions, which influence the expected downstream prices. The baseline probability of high prices is itself a random variable that can either be high or low: $x \in$ $\left\{x_{H}, x_{L}\right\}$ with $0<x_{L}<x_{H}<1-\eta$. The ex-ante probability of a low baseline probability is given by $\alpha_{x}$. The mean of the baseline probability is denoted by $x_{M}=\alpha_{x} x_{L}+\left(1-\alpha_{x}\right) x_{H}$.

There are two layers of regulation, a benevolent (but uninformed) legislator, and a better informed (but corruptible) regulator. The regulator has to provide an assessment of the state of the industry, and the legislator specifies ex-ante a regulation that maps the regulator's initial assessment and resulting market prices into transfers. The regulator receives a signal $\widehat{x} \in\left\{x_{L}, x_{M}, x_{H}\right\}$ about the baseline probability, where $\widehat{x}=x_{L}$ and $\widehat{x}=x_{H}$ mean that the regulator gets evidence that reveals the baseline probability $x$ (which happens with probability $\phi_{x}$ ), while a signal $\widehat{x}=x_{M}$ means that the regulator gets no information about the baseline 
probability (which happens with probability $\left(1-\phi_{x}\right)$ ).

The regulator's assessment consists of an announcement $\widetilde{x} \in\left\{x_{L}, x_{M}, x_{H}\right\}$ of his signal. The regulator can suppress evidence but cannot fake it, i.e. he can state $\widetilde{x}=x_{M}$ if $\widehat{x}=x_{L}$ or $\widehat{x}=x_{H}$, but he cannot state $\widetilde{x}=x_{L}$ or $\widetilde{x}=x_{H}$ if $\widehat{x}=x_{M}$. The firm receives the same signal as the regulator (we later discuss alternative informational assumptions). If the regulator got evidence of a low or high baseline probability, the firm can bribe him to suppress the evidence by announcing $\widetilde{x}=x_{M}$. A bribe costs the firm a fixed amount $b_{x}>0$. If the regulator is not bribed, he reveals truthfully $\widetilde{x}=\widehat{x}$.

The legislator decides on a regulation $\left(t_{L}(\widetilde{x}), t_{H}(\widetilde{x})\right)$ that maps the regulator's assessment and the realized market prices into transfers to the firm. The legislator maximizes a welfare criterion

$$
W=S(p)-c e-\beta t-\gamma B
$$

where $S(p)$ is a combined measure of consumer surplus and the profits of downstream firms, $t$ denotes the transfers to the firm, and $B$ are the bribes. The parameter $\beta, \beta>0$, denotes shadow cost of public funds to finance the transfers. The legislator may dislike bribes, $\gamma \geq 0 .{ }^{10}$ We take the other "operational" profits of the firm as given, and normalize it to zero. All players are risk neutral.

The timing and information structure are as follows. First, the legislator chooses a regulation $\left(t_{L}(\widetilde{x}), t_{H}(\widetilde{x})\right)$. Then nature draws the baseline probability of high prices $x$ and the corresponding signal $\widehat{x}$. The signal $\widehat{x}$ is revealed to the regulator and the firm and the firm then decides on bribing the regulator to suppress evidence. Afterwards the regulator makes his assessment $\widetilde{x}$. The firm can then accept or reject the resulting regulation. If the firm rejects, it gets an outside payoff of 0 and welfare is also 0 . If the firm accepts, it decides on effort $e$. Finally, the market price $p$ realizes and transfers according to the regulation are conducted. Figure 1 provides an overview.

We focus on "essential" services, i.e., we assume in all what follows that the legislator never wants that the firm does not participate. Furthermore, to avoid uninteresting case distinc-

\footnotetext{
${ }^{10}$ Bribes might, in the next section, also include manipulation payments from the network firm to the financial market participants. That bribes, while being transfers, might reduce welfare can be motivated by the fact that illegal money can be used less efficiently than legal money, e.g., because it needs to be transferred to certain foreign account or to be held in cash. Furthermore, one might think that society dislikes the breaking of rules as such.
} 


\begin{tabular}{ccccc}
\hline & & & & \\
$\begin{array}{c}\text { Legislator } \\
\text { decides on }\end{array}$ & $\begin{array}{c}\text { Nature draws the } \\
\text { baseline }\end{array}$ & $\begin{array}{c}\text { Firm decides on } \\
\text { bribes, regulator }\end{array}$ & $\begin{array}{c}\text { Firm decides on } \\
\text { participation; if }\end{array}$ & $\begin{array}{c}\text { Realization of } \\
\text { market price } p\end{array}$ \\
regulation & probability $x$, & announces & participating, the & and payments \\
$\left(t_{L}(\tilde{x}), t_{H}(\tilde{x})\right)$ & and the signal & $\tilde{x} \in\left\{x_{L}, x_{M}, x_{H}\right\}$ & $\begin{array}{c}\text { firm chooses } \\
\text { action } e\end{array}$ & \\
& $\hat{x} \in\left\{x_{L}, x_{M}, x_{H}\right\}$ & & action &
\end{tabular}

Figure 1: Regulation using only outcome contingent transfer

tions, we always assume that the social benefit from high effort $(e=1)$ is sufficiently large such that the legislator always wants to induce it.

We denote by

$$
\Delta_{t}=t_{L}-t_{H}
$$

the difference of the transfers under low and high market prices. The variable $\Delta_{t}$ can be interpreted as a bonus (which might be negative) that the firm receives from the regulatory transfers if low prices realize. The incentive constraint that the firm chooses high effort $e=1$ requires that the expected gain from higher transfers exceeds the cost of high effort, i.e. $x t_{H}+(1-x) t_{L}-c \geq(x+\eta) t_{H}+(1-x-\eta) t_{L}$, implying

$$
\eta \Delta_{t} \geq c
$$

The firm's participation constraint is given by

$$
t_{H}+(1-\widehat{x}) \Delta_{t} \geq c .
$$

Since the legislator does not observe the signal $\widehat{x}$, the relevant transfers can only be based on the regulator's assessment $\widetilde{x}$. If bribes were not possible, the lowest transfers $t_{H}$ that always ensure participation would be given by

$$
t_{H}=c-(1-\widetilde{x}) \Delta_{t}
$$

Under such regulations, the only potentially profitable form of bribes is to induce omission of evidence for a low baseline probability, i.e. bribing the regulator to announce $\widetilde{x}=x_{M}$ if $\widehat{x}=x_{L}$. The firm could then obtain a rent of

$$
R_{x}\left(\widehat{x} \mid \Delta_{t}\right)= \begin{cases}\max \left\{\left(x_{M}-x_{L}\right) \Delta_{t}-b_{x}, 0\right\} & \text { if } \widehat{x}=x_{L} \\ 0 & \text { otherwise }\end{cases}
$$

The following result shows that under the welfare maximizing regulation the firm indeed receives this rent. However, since bribes are welfare reducing, it is optimal to avoid the bribe by leaving the firm a rent in case $\widetilde{x}=x_{L}$ is announced. 
Proposition 1 Without forward contracts, welfare is maximized using a regulation with following structure: The bonus for low prices is set to

$$
\Delta_{t}=\frac{c}{\eta}
$$

and $t_{H}(\widetilde{x})$ is set such that bribes will not be paid and the firm gets its minimum rents of $R_{x}\left(x \mid \Delta_{t}\right)$.

Proof. Setting $\Delta_{t}=\frac{c}{\eta}$ ensures $e=1$. Let

$$
t_{H}(\widetilde{x})=c-(1-\widetilde{x}) \Delta_{t}+\left\{\begin{array}{ll}
\max \left\{\left(x_{M}-x_{L}\right) \Delta_{t}-b_{x}, 0\right\} & \text { if } \widehat{x}=x_{L} \\
0 & \text { otherwise }
\end{array} .\right.
$$

This implies the rents of (7). These are the minimum rents possible, due to the following arguments: (i) Conditioning on the announcement is optimal: The regulation is either conditional on the regulator's announcement, or independent of the announcement. If it is independent, to guarantee participation in all cases, including $\widehat{x}=x_{H}$, the lowest transfers to the firm satisfy $x_{H} t_{H}+\left(1-x_{H}\right) t_{L}-c=0$. Conditioning on the announcement as described in the proposition yields lower costly rents if $\widehat{x}=x_{H}$, because then no misreporting is possible and the participation is guaranteed already if $x_{M} t_{H}+\left(1-x_{M}\right) t_{L}-c=0$ holds. (ii) It is optimal to avoid bribes. Consider a regulation conditioning on the regulator's announcement. Now assume, that it would be worthwhile for the firm to bribe the regulator under this regulation, and this would in some state $\widehat{x}_{i}$ yield a payoff $\Pi\left(\widehat{x}_{i}, \widetilde{x} \neq \widehat{x}_{i}\right) \geq \Pi\left(\widehat{x}_{i}, \widehat{x}_{i}\right)$. Then, a regulation adding $\Pi\left(\widehat{x}_{i}, \widetilde{x} \neq \widehat{x}_{i}\right)-\Pi\left(\widehat{x}_{i}, \widehat{x}_{i}\right)-b_{x}$ to $\Pi\left(\widehat{x}_{i}, \widehat{x}_{i}\right)$ takes away the incentive to bribe, leaves rents unaltered, but avoids the weakly welfare reducing bribes. (iii) Consider an alternative conditional regulation that yields lower rents. Since rents are zero under the proposed regulation for $\widehat{x}_{H}$ and $\widehat{x}_{M}$, this would imply that rents are lower for $\widehat{x}_{L}$, but this would not be bribe free and therefore not optimal according to (ii).

\subsection{Optimal regulation with forward contracts}

We now introduce regulations that can propose to the firm to sell forward contracts in an auction. We restrict attention to simple forward contracts of the form that for every forward contract sold, the firm will in the future, i.e., after the realization of the downstream price, have to pay the buyer of the contract the downstream price $p$. The regulation determines the quantity $q(\widetilde{x})$ of forward contracts that has to be auctioned off and it determines the transfers to be paid to the firm. The regulation is not allowed to condition on the outcome of the auction (we discuss this assumption in Section 5.3). 


\begin{tabular}{|c|c|c|c|c|}
\hline & & & & \\
\hline $\begin{array}{l}\text { Legislator } \\
\text { determines } q \\
\text { and } \\
\left(t_{L}(\tilde{x}), t_{H}(\tilde{x})\right)\end{array}$ & $\begin{array}{c}\text { Nature draws the } \\
\text { baseline } \\
\text { probability } x \\
\text { and the signal } \\
\hat{x} \in\left\{x_{L}, x_{M}, x_{H}\right\}\end{array}$ & $\begin{array}{l}\text { Firm decides on } \\
\text { bribes, regulator } \\
\text { announces } \\
\tilde{x} \in\left\{x_{L}, x_{M}, x_{H}\right\}\end{array}$ & $\begin{array}{l}\text { Firm decides on } \\
\text { participation; if } \\
\text { participating, the } \\
\text { firm sells q } \\
\text { forward contracts } \\
\text { in an auction and } \\
\text { chooses action } e\end{array}$ & $\begin{array}{c}\text { Realization of } \\
\text { market price } p \\
\text { and payments } \\
\text { (transfers and } \\
\text { payments on } \\
\text { the forward } \\
\text { contracts) }\end{array}$ \\
\hline
\end{tabular}

Figure 2: Regulation using transfers and forward contracts

There are several risk-neutral, perfectly competitive financial investors who commonly learn the signal $\widehat{x}$. Since the financial market is competitive, total auction revenues are equal to expected returns, which, under a regulation that induces high effort, are given by

$$
A=\left(\widehat{x} p_{H}+(1-\widehat{x}) p_{L}\right) q
$$

We define by

$$
\Delta_{f}=\left(p_{H}-p_{L}\right) q
$$

the amount that the firm has to pay less to the buyers of the forward contracts if the downstream price $p_{L}$ instead of $p_{H}$ realizes. The variable $\Delta_{f}$ can be interpreted as a bonus that the firm receives from the forward contracts if low prices realize. Figure (2) summarizes the timing for the case that forward contracts are used.

In contrast to outcome contingent transfers, a regulation using forward contracts can solve the moral hazard problem without causing any costly rents.

Proposition 2 The following regulation achieves the first-best welfare optimal outcome: The quantity of forward contracts $q$ is independent of the announcement $\widetilde{x}$ and chosen such that

$$
\Delta_{f}=\frac{c}{\eta}
$$

Regulatory transfers are independent of the realized price and the regulator's announcement and are characterized by

$$
\Delta_{t}=0, \text { and } t_{H}(\widetilde{x}, \theta)=-c .
$$

There are never bribes and the firm always gets zero expected rents.

Proof. It is straightforward to check that the described regulation satisfies the incentive compatibility condition and the participation constraint of the firm. Furthermore, the return on bribes is zero. 
The intuition why the first best outcome can be achieved is simple. We have assumed that the financial market is as well informed as the firm, hence there is no asymmetric information problem. The only difference to the previous case is that the incentives are provided by the financial market interaction, which rules out that bribes can create profits. Since there are no payments depending on the regulator's behavior (the regulator is dispensable under this kind of regulation), bribing the regulator makes no sense.

Note that there is no coalition of the network firm and financial investors that could jointly benefit by possible bribes from the network firm to the investors that shall induce too high or too low bids in the auction. That is because the auction revenues do not influence the regulatory payments or the future payment obligations from the sold forward contracts. Bribing a bidder to pay too much in the auction, would require as a compensation for the overpaying bidder exactly the additional proceeds from the auction. Bribing a bidder to make lower bids makes no sense as this would directly reduce the profits of the network firm.

\section{Optimal regulation with private information by the firm}

Since it might well be that the firm has private information, we add to the previous analysis a problem of adverse selection. We assume that the firm has private information about a parameter $\theta$ that influences the distribution of prices. The probability of high prices is

$$
\operatorname{Pr}\left(p=p_{H}\right)=x+\theta+\eta(1-e)
$$

The parameter $\theta$ can take two values, $\theta \in\left\{\theta_{L}, \theta_{H}\right\}$, with $0<\theta_{L}<\theta_{H}<1-x_{H}-\eta$. We refer to $\theta_{L}$ as an efficient type and to $\theta_{H}$ as an inefficient type. ${ }^{11}$ The ex-ante probability of an efficient type $\theta_{L}$ is $\alpha_{\theta}$ and we denote the expected value of $\theta$ by $\theta_{M}=\alpha_{\theta} \theta_{L}+\left(1-\alpha_{\theta}\right) \theta_{H}$. The financial market and the regulator only observes a signal $\widehat{\theta}$ that can take one of the values $\left\{\theta_{L}, \theta_{M}, \theta_{H}\right\}$, where $\widehat{\theta}=\theta_{L}$ and $\widehat{\theta}=\theta_{H}$ indicate evidence of an efficient and of an inefficient type, respectively, while $\widehat{\theta}=\theta_{M}$ indicates no evidence of a type. Evidence of the type is obtained with probability $\phi_{\theta}$, irrespective of whether $\theta=\theta_{L}$ or $\theta=\theta_{H}$.

The regulator's assessment now consists of a pair of announcements $(\widetilde{x}, \widetilde{\theta})$ that can disclose evidence of the baseline probability $x$ and of the firm's type $\theta$. For simplicity, we assume that the firm has to bribe separately for concealing evidence of $x$ and $\theta$, with bribing costs

\footnotetext{
${ }^{11}$ An alternative interpretation would be that the firm has superior information on the baseline probability of high prices, which would then be $(x+\theta)$.
} 
of $b_{x}$ and $b_{\theta}$, respectively. Again, we restrict attention to the case that it is welfare optimal that the firm always accepts the regulation and chooses high effort. And we maintain the assumption that, also for the firm's type, the regulator can suppress information, but cannot make up information.

It is instructive to first analyze the firm's minimal rents due to private information about its type under a regulation that does not use forward contracts, i.e. $\Delta_{t}>0$ and $\Delta_{f}=0$. If the firm's type is not revealed, $\widehat{\theta}=\theta_{M}$, the participation constraint has to hold for the inefficient type $\theta_{H}$, i.e. an efficient type $\theta_{L}$ can ensure itself a rent of $\left(\theta_{H}-\theta_{L}\right) \Delta_{t}$. If the regulator receives a signal that reveals an efficient type, $\widehat{\theta}=\theta_{L}$, the possibility of bribing the regulator to conceal this evidence guarantees the efficient firm a rent of $\max \left\{\left(\theta_{H}-\theta_{L}\right) \Delta_{t}-b_{\theta}, 0\right\}$. An inefficient type receives no rent.

Let us now consider the opposite case, where forward contracts are used, but the regulatory transfer does not depend on the realized downstream prices, i.e., $\Delta_{t}=0$ and $\Delta_{f}>0$. In contrast to the case without private information, it is now no longer true that the regulatory transfer has only to capture the cost $c$ of the efficient action. Now, the transfer must be higher in case that the firm's type is not revealed to the financial market and to the regulator.

Imagine the firm is of the inefficient type, but this is not revealed, i.e., $\theta=\theta_{H}$ and $\widehat{\theta}=\theta_{M}$. The financial market will only pay the average price for the forward contract, $p_{H}\left(\widehat{x}+\theta_{M}\right)+$ $p_{L}\left(1-\left(\widehat{x}+\theta_{M}\right)\right)$, while the firm knows that its expected payments per contract will be higher, namely $p_{H}\left(\widehat{x}+\theta_{H}\right)+p_{L}\left(1-\left(\widehat{x}+\theta_{H}\right)\right)$. Thus, the inefficient type would face an expected loss of $\left(\theta_{H}-\theta_{M}\right) \Delta_{t}$ from its sale of forward contracts. It is willing to participate only if it receives from the regulator a "reimbursement payment" that covers this loss. Thus, in case that the type is unknown to the regulator, the regulator must pay a flat transfer of $\left(\theta_{H}-\theta_{M}\right) \Delta_{t}+c$. This implies that, if the firm turns out to be inefficient, it receives no rent (zero profits), while it does receive a rent if it is efficient. The rent equals $\left(\theta_{H}-\theta_{M}\right) \Delta_{f}+$ $\left(\theta_{M}-\theta_{L}\right) \Delta_{f}=\left(\theta_{H}-\theta_{L}\right) \Delta_{f}$. The first term is the reimbursement payment (which ex post turns out to be unnecessary), the second term is the profit the efficient firm makes when trading with an uninformed financial market.

The reimbursement payment required for the case that the type of the firm is not revealed provides incentives to bribe the regulator in the cases where the type is revealed. If it is revealed, the interaction with the financial market yields zero expected profits for both types, and no reimbursement payment is required. If no bribing was possible, this would imply that the participation constraint for both types would already be satisfied by a flat transfer of consisting of $c$ only (to cover the effort cost). 
However, if manipulating the regulator is possible, both types can now gain from bribing the regulator to announce "no information" $\left(\widetilde{\theta}=\theta_{m}\right)$, which would then trigger the reimbursement payment. ${ }^{12}$ To avoid this, the firm must receive a rent also in the case that the type is revealed. A flat transfer of $\max \left\{\left(\theta_{H}-\theta_{M}\right) \Delta_{f}-b_{\theta}, 0\right\}+c$ exactly offsets the incentive for obtaining (surreptitiously) the reimbursement payment. This implies that with forward contracts, not only the efficient type receives a rent (like in the case of outcome contingent transfers), but also the inefficient type.

By adding up the rents of the two cases $(i) \Delta_{t}=0$ and $\Delta_{f}>0$ and $(i i) \Delta_{t}>0$ and $\Delta_{f}=0$, we can derive that, generally, the minimum rents from the adverse section problem are:

$$
R_{\theta}\left(\widehat{\theta}, \theta \mid \Delta_{t}, \Delta_{f}\right)= \begin{cases}\left(\theta_{H}-\theta_{L}\right)\left(\Delta_{t}+\Delta_{f}\right) & \text { if } \widehat{\theta}=\theta_{M} \text { and } \theta=\theta_{L} \\ 0 & \text { if } \widehat{\theta}=\theta_{M} \text { and } \theta=\theta_{H} \\ \max \left\{\left(\theta_{H}-\theta_{L}\right) \Delta_{t}+\left(\theta_{H}-\theta_{M}\right) \Delta_{f}-b_{\theta}, 0\right\} & \text { if } \widehat{\theta}=\theta_{L} \text { and } \theta=\theta_{L} \\ \max \left\{\left(\theta_{H}-\theta_{M}\right) \Delta_{f}-b_{\theta}, 0\right\} & \text { if } \widehat{\theta}=\theta_{H} \text { and } \theta=\theta_{H}\end{cases}
$$

If the type of the firm is not revealed (the first two lines with $\widehat{\theta}=\theta_{M}$ ), the rent is just the usual information rent for the efficient type (line 1), while it is zero for the inefficient type. If the type is revealed, the firm will receive rents in order to prevent it from bribing the regulator to suppress the information received, which is just the sum of the rents for the extreme cases that use either price contingent transfers, or forward contract. If the firm's type is known to be efficient, the firm gets a rent from either type of regulation. However, if the firm is inefficient, a rent is generated only from the reimbursement payment stemming from the use of financial contracts.

In addition, the firm still gets the rents from the option to bribe the regulator not to disclose a low baseline probability if $\widehat{x}=x_{L}$. Due to our assumption that the regulator has to be bribed separately for concealing evidence of the baseline probability and of the firm's type, also the rents are additive. Thus, the total minimum costly ${ }^{13}$ rents as functions of $\Delta_{t}$ and

\footnotetext{
${ }^{12}$ If this happened, the auction revenues to be expected due to this announcement and the actual auction revenues would differ. This does not matter in the framework proposed since we assumed that the regulatory rule can not condition on the auction revenues. We discuss regulations that condition on the auction revenues in Section 5.3.

${ }^{13}$ Ex post, the firm's rent and the costly rent can differ. This happens if $\widehat{\theta}=\theta_{M}$ : if $\widehat{\theta}=\theta_{M}$ and $\theta=\theta_{L}$, the costly rent is only the reimbursement payment, $\left(\theta_{H}-\theta_{M}\right) \Delta_{f}$, while the rest of the firm's rent, $\left(\theta_{M}-\theta_{L}\right) \Delta_{f}$, is paid by the financial market, i.e., is only a transfer between firms. This loss is exactly offset by the financial market's profit if $\widehat{\theta}=\theta_{M}$ and $\theta=\theta_{H}$. This profit is financed by the transfers (the reimbursement payment) from the regulator to the firm, i.e., in this case, ex post, the firm's rent (which is zero) falls short of the socially costly transfers. Ex ante, due to the zero profit condition for the financial market, costly rents and the firm's rent must be identical.
} 
$\Delta_{f}$ are given by

$$
R\left(\widehat{x}, \widehat{\theta}, \theta \mid \Delta_{t}, \Delta_{f}\right)=R_{x}\left(\widehat{x} \mid \Delta_{t}, \Delta_{f}\right)+R_{\theta}\left(\widehat{\theta}, \theta \mid \Delta_{t}, \Delta_{f}\right) .
$$

To satisfy the incentive constraints for high effort we need $\Delta_{f}+\Delta_{t} \geq \frac{c}{\eta}$. Even though positive values of $\Delta_{f}$ can yield positive rents of for an inefficient type, it turns out that exante expected rents are minimized by setting $\Delta_{f}=\frac{c}{\eta}$ and $\Delta_{t}=0$, i.e., optimal regulation uses forward contracts only.

Proposition 3 There is always a welfare maximizing regulation with $\Delta_{t}=0$, and $\Delta_{f}=\frac{c}{\eta}$. Total welfare is strictly increasing in the cost of bribes $b_{\theta}$, as long as $b_{\theta}$ is sufficiently low.

Proof. Maximization of expected total welfare maximization is in our set-up equivalent to minimization of the ex-ante expected rents of the firm. Following the arguments above, we find that the lowest ex-ante expected rents that guarantee participation of the firms are given by

$$
\begin{aligned}
E\left[R\left(\Delta_{f}, \Delta_{t}\right)\right] & =\alpha_{x} \phi_{x} R_{x}\left(x_{L}\right)+\left(1-\alpha_{\theta}\right) \phi_{\theta} R_{\theta}\left(\theta_{H}, \theta_{H}\right) \\
& +\alpha_{\theta} \phi_{\theta} R_{\theta}\left(\theta_{L}, \theta_{L}\right)+\alpha_{\theta}\left(1-\phi_{\theta}\right) R_{\theta}\left(\theta_{M}, \theta_{L}\right) \\
& =\alpha_{x} \phi_{x} \max \left\{\left(x_{M}-x_{L}\right) \Delta_{t}-b_{x}, 0\right\} \\
& +\left(1-\alpha_{\theta}\right) \phi_{\theta} \max \left\{\left(\theta_{H}-\theta_{M}\right) \Delta_{f}-b_{\theta}, 0\right\} \\
& +\alpha_{\theta} \phi_{\theta} \max \left\{\left(\theta_{H}-\theta_{L}\right) \Delta_{t}+\left(\theta_{H}-\theta_{M}\right) \Delta_{f}-b_{\theta}, 0\right\} \\
& +\alpha_{\theta}\left(1-\phi_{\theta}\right)\left(\theta_{H}-\theta_{L}\right)\left(\Delta_{t}+\Delta_{f}\right)
\end{aligned}
$$

For the case $\left(\theta_{H}-\theta_{M}\right) \Delta_{f}-b_{\theta}<0$ it is evident that choosing $\Delta_{f}=\frac{c}{\eta}$ and $\Delta_{t}=0$ minimizes the expected rents, since the second term in the sum drops out. Consider the case that $\left(\theta_{H}-\theta_{M}\right) \Delta_{f}-b_{\theta} \geq 0$, implying that

$$
\begin{aligned}
E\left[R\left(\Delta_{f}, \Delta_{t}\right)\right] & =\alpha_{x} \phi_{x} \max \left\{\left(x_{M}-x_{L}\right) \Delta_{t}-b_{x}, 0\right\} \\
& +\Delta_{f}\left(\phi_{\theta}\left(\theta_{H}-\theta_{M}\right)+\alpha_{\theta}\left(1-\phi_{\theta}\right)\left(\theta_{H}-\theta_{L}\right)\right) \\
& +\Delta_{t} \alpha_{\theta}\left(\theta_{H}-\theta_{L}\right) \\
& =\alpha_{x} \phi_{x} \max \left\{\left(x_{M}-x_{L}\right) \Delta_{t}-b_{x}, 0\right\} \\
& +\left(\Delta_{f}+\Delta_{t}\right) \alpha_{\theta}\left(\theta_{H}-\theta_{L}\right) .
\end{aligned}
$$

Then, a marginal increase in $\Delta_{f}$ increases the expected rents by

$$
\frac{\partial E\left[R\left(\Delta_{f}, \Delta_{t}\right)\right]}{\partial \Delta_{f}}=\alpha_{\theta}\left(\theta_{H}-\theta_{L}\right)
$$


while a marginal increase in $\Delta_{t}$ increases the expected rent by:

$$
\frac{\partial E\left[R\left(\Delta_{f}, \Delta_{t}\right)\right]}{\partial \Delta_{t}}=\alpha_{\theta}\left(\theta_{H}-\theta_{L}\right)+\frac{\partial R_{x}\left(\widehat{x} \mid \Delta_{t}, \Delta_{f}\right)}{\partial \Delta_{t}} .
$$

i.e., it increases rents by the same amount (if $\frac{\partial R_{x}\left(\widehat{x} \mid \Delta_{t}, \Delta_{f}\right)}{\partial \Delta_{t}}=0$ ), or (otherwise, which happens if $b_{x}$ is sufficiently small) strictly more. Hence, it is always optimal to set $\Delta_{t}=0$ and $\Delta_{f}=\frac{c}{\eta}$.

We know from Proposition 2 that forward contracts tend to be better suited to solve the moral hazard problem. It is not obvious, however, that the superiority of forward contracts still holds in the presence of an additional adverse selection problem, since forward contracts create rents not only for the efficient type, but also for the inefficient type, while outcome contingent transfers yield rents only for the efficient type.

The proof of Proposition 3 shows that forward contracts are as well suited to solve the adverse selection problem as outcome contingent transfers. Imagine that $\Delta_{f}=\Delta_{t}=\frac{1}{2} \frac{c}{\eta}$ (we already know that for incentive compatibility we need $\Delta_{f}+\Delta_{t}=\frac{c}{\eta}$ ). In that case, ex-post rents due to outcome contingent transfers occur less frequently (only if the firm is an efficient type), but if they occur, they are higher than the rents due to forward contracts. To ensure participation, the rents due to outcome contingent payments need to cover the difference between the efficient and the inefficient type, $\left(\theta_{H}-\theta_{L}\right) \Delta_{t}$, while the reimbursement payment required with forward contracts needs to cover only the difference between the "average" type and the low type, $\left(\theta_{M}-\theta_{L}\right) \Delta_{f}$. Increasing the weight on $\Delta_{f}$ therefore has two opposing effects (less weight on those rents which occur only with some probability, but lower level of ex post rents if both types of rents occur), which exactly offset each other with respect to the rent caused by adverse selection. However, with outcome contingent transfers, we additionally need to pay rents $R_{x}$ to solve the moral hazard problem, which makes forward contracts the preferred regulatory tool.

\section{Robustness}

\subsection{Alternative Information assumptions}

So far we assumed an information advantage of the firm on its type, while the financial market and the regulator are symmetrically informed about the baseline probability, and they receive the same information about the type. This symmetry assumption might be violated in various ways. 
Regulator holding superior information One might argue that the regulator has superior knowledge about the firm's type $\theta$ compared to the financial market, since the regulator can force the firm to reveal certain information (e.g., cost information). To analyze the case where the regulator holds superior information, assume that only the regulator can get a signal $\widehat{\theta}$ about the network firm's type $\theta$, while the financial market never obtains direct evidence of the type. If and only if the regulator announces evidence for a low or high type, i.e. $\tilde{\theta} \in\left\{\theta_{L}, \theta_{H}\right\}$, the type is also revealed to financial investors. As before, we assume that the regulator cannot make up evidence but may hide information.

For the following arguments assume $\Delta_{t}=0$ and $\Delta_{f}=\frac{c}{\eta}$, and assume that the financial market believes that the regulator announces truthfully. ${ }^{14}$ Consider the case that the regulator gets a signal for an inefficient firm, i.e. $\widehat{\theta}=\theta_{H}$. In contrast to the case that the financial market is informed, the inefficient firm can no longer benefit from bribing the regulator to suppress this information. As long as the financial market remains uninformed about the type, the firm's auction proceeds will fall short of the expected payments of the firm. This loss is exactly equal to the reimbursement payment, which the firm can obtain by bribing the regulator. Thus, an inefficient type does not obtain a rent in this case.

Consider now the case that an efficient type is revealed to the regulator, i.e. $\widehat{\theta}=\theta_{L}$. Bribing the regulator produces two kinds of returns. First, the firm receives the reimbursement payment of $\left(\theta_{H}-\theta_{M}\right) \Delta_{f}$. Second, the financial market remains uninformed, and the efficient firm can realize the profit from interacting with an uninformed financial market, which equals, $\left(\theta_{M}-\theta_{L}\right) \Delta_{f}$. To avoid bribes, the regulation must require that if the regulator announces that the type is efficient, the firm must receive a flat transfer of $\max \left\{\left(\theta_{H}-\theta_{L}\right) \Delta_{f}-b_{\theta}\right\}+c$. This yields exactly the same rents from the adverse selection problem as a regulation relying only on outcome contingent transfers, $\Delta_{f}=0$ and $\Delta_{t}=\frac{c}{\eta}$, where by the same arguments as before, only the efficient type receives the usual information rent of $\left(\theta_{H}-\theta_{L}\right) \Delta_{f}$ and the inefficient type never receives any rent. While rents from the adverse selection problem are again identical, the additional rent required to solve the moral hazard problem tips the regulatory regime in favor of using forward contracts only.

Financial market holding superior information Alternatively, one might argue that financial market participants have superior information compared to the regulator, e.g., due to better paid and more able personnel, availability of international comparisons etc. If the financial market has better information about the baseline probability than the regulator, neither the

\footnotetext{
${ }^{14}$ Under optimal regulations the firm will have no incentives to bribe. Then consistent beliefs for financial investors are that the regulator's announcements are truthful.
} 
optimal regulation nor the firms expected rents change. Outcome contingent transfers are not affected by this alternative informational assumption. Forward contracts again solve the moral hazard problem without cost, while the cost from solving the adverse selection problem are the reimbursement payments (paid to both types), which must be such that the firm participates even in the (still possible) case that the financial market interaction leads to a loss for the inefficient firm. (This case has just become less likely since the type is known now more frequently known by the financial market, ensuring zero profit from the financial market interaction).

Although the financial market is better informed here, involving them in the regulation by using forward contracts does not reduce the rents. This could happen only if the financial market would always perfectly recognize an inefficient type (and if the regulator knows this); then the regulation could reduce the fixed transfer. The result that only perfect information of the financial market can reduce the rent is due to our assumption that the firm delivers an essential service, i.e., the participation constraint must always hold. If this assumption would be relaxed, superior information by financial markets can be beneficial more generally.

The firm holding inferior information Another potentially plausible case is that the financial market is even better informed about the future downstream prices than the firm itself. This might be due to the fact that the firm is a firm that focuses only on the network part, while the financial players can easily collect information also about the spot market and can analyze the information in a very effective way.

An easy way to fit this into our analysis would be to add a mean preserving error term $\theta_{F M}$ into the probability of high prices, $\operatorname{Pr}\left(p_{H}\right)=x+\theta+\eta(1-e)+\theta_{F M}, E\left[\theta_{F M}\right]=0$. The financial market knows the realization of $\theta_{F M}$, while the regulator and the firm do not know it. If we maintain all other assumptions from the previous section, such inferior information of the firm does not change the result of Proposition 3. Competition in the financial market will ensure that the profit from the financial market interaction is zero (in expectation), given the information of the financial market. What changes compared to the previous analysis is that the firm has to calculate with an expected profit from the financial market interaction, based on its knowledge about the own type, instead of being able to exactly predict this profit. Since we assumed that the firm is risk neutral, this does not matter for the firm's behavior.

\subsection{Costly auctions}

So far we assumed that there were no costs associated with auctioning off the forward contracts. However, there can be several reasons why auction revenues might be lower than 
expected income from the forward contracts, e.g. financial market participants might have market power (i.e., buyer power vis a vis the firm), they might be risk averse, or there might be technological transaction costs. Consider the case that auction revenues are only a fraction $(1-k)$ of the expected income:

$$
A=(1-k) q\left((\widehat{x}+\widehat{\theta}) p_{H}+(1-\widehat{x}-\widehat{\theta}) p_{L}\right)
$$

where $k \in \mathbb{R}$ is an exogenous transaction cost parameter. Let $K$ denote the expected total transaction cost of the auctions:

$$
K=k q p_{M}
$$

where $p_{M}=\left(x_{M}+\theta_{M}\right) p_{H}+\left(1-x_{M}-\theta_{M}\right) p_{L}$ is the ex-ante expected market price. By the definition of $\Delta_{f}$, we have $q=\Delta_{f} /\left(p_{H}-p_{L}\right)$. A marginal increase in $\Delta_{f}$ then leads to a marginal increase in expected total transaction costs by

$$
\frac{\partial K}{\partial \Delta_{f}}=\frac{\partial K}{\partial q} \frac{\partial q}{\partial \Delta_{f}}=k \frac{p_{M}}{p_{H}-p_{L}} .
$$

Since this is positive, it immediately follows that if the legislator attaches a negative welfare weight to the transaction costs, the use of forward contracts therefore becomes less attractive. A very high negative weight or a large size of the transaction costs parameter $k$ can easily make it optimal to fully abstain from using forward contracts.

However, even if the legislator attaches no negative welfare weight to the transaction costs (e.g., because they reflect buyer power of the financial market, and the legislator is indifferent with respect to transfers between the firm and the financial market), the presence of transaction costs can make forward contracts less attractive, since the firm has to be reimbursed for the lost auction revenues by higher fixed transfers.

For the optimal choices of $\Delta_{t}$ and $\Delta_{f}$, the adverse selection problem again plays no role. By the last section's arguments, from an ex-ante perspective outcome contingent transfers and financial contracts are equally vulnerable to bribes to conceal evidence on the type (see (15) in the proof of Proposition 3). What matters are (i) the rents due to the moral hazard problem, i.e., the rents the firm can achieve by bribing the regulator to omit evidence of a low baseline probability $x_{L}$ if outcome contingent transfers are used (the term (14) in the proof of Proposition 3), and (ii) the additional effect of transaction cost, $\frac{\partial K}{\partial \Delta_{f}}$.

The first effect favors the use of forward contracts, the second makes them less attractive. The first effect is absent if bribing the regulator for misreporting the baseline probability is too costly, i.e., if $\left(x_{M}-x_{L}\right) \frac{c}{\eta} \leq b_{x}$. In that case, only the second effect is present and it is optimal not to use any forward contracts, i.e. to set $\Delta_{t}=\frac{c}{\eta}$ and $\Delta_{f}=0$. 
If the first effect is present, i.e., $\left(x_{M}-x_{L}\right) \frac{c}{\eta}>b_{x}$, then it follows that is optimal to use forward contracts if and only if

$$
\frac{\partial K}{\partial \Delta_{f}} \leq \alpha_{x} \phi_{x}\left(x_{M}-x_{L}\right)
$$

where the left hand side is just the first effect, and the right hand side is the second effect, i.e., the marginal impact of a change of $\Delta_{t}$ on (14). Using (20) this implies:

$$
k \leq \phi_{x} \alpha_{x}\left(1-\alpha_{x}\right)\left(x_{H}-x_{L}\right) \frac{p_{H}-p_{L}}{p_{M}} .
$$

Using forward contracts is beneficial only if the first effect (the expected negative impact of bribes to omit evidence for a low baseline probability) is sufficiently large; condition (22) clarifies what this exactly means. Using forward contracts is beneficial if (a) the baseline probability is frequently known, i.e. $\phi_{x}$ is large, (b) the uncertainty about the baseline probability, measured by $\alpha_{x}\left(1-\alpha_{x}\right)$, is large, and (c) if the spread in the baseline probabilities $\left(x_{H}-x_{L}\right)$ is large; finally, (d) a large normalized spread in downstream prices $\frac{p_{H}-p_{L}}{p_{M}}$ makes the use of forward contracts more beneficial, because forward contracts can then more effectively provide incentives for high effort.

According to (14), for small values of $\Delta_{t}$, up to the threshold $\frac{b_{x}}{x_{M}-x_{L}}$, the first effect is not present and $\Delta_{t}$ does not cause any costly rents. The "bonus" $\Delta_{t}$ is just too small to make bribing the regulator profitable, and therefore, no rent has to be granted to avoid the bribe. Thus, $\Delta_{t}>0$ should be used, since this can reduce $\Delta_{f}$, where the latter is costly due to the transaction cost. For larger values of $\Delta_{t}$ it is no longer true that it is cheaper to provide incentives by substituting $\Delta_{f}$ by $\Delta_{t}$. We just derived that given $k>0$ and provided that condition (22) holds, incentives are cheaper to provide by using $\Delta_{f}$ instead of $\Delta_{t}$. Therefore, in this case the optimal regulation has the structure $\Delta_{t}=\frac{b_{x}}{x_{M}-x_{L}}$ and $\Delta_{f}=\frac{c}{\eta}-\Delta_{t}$. Consequently, with positive transaction cost in the auction, which lead to auction proceeds falling short of the expected value of the forward contracts, it can become optimal to use both instruments, forward contracts and outcome contingent transfers. ${ }^{15}$

Whether it is a sensible assumption that auction revenues are in expectation smaller than expected payments, depends on the application. Auction revenues might also exceed expected payments if there are many counterparties that want to buy forward contracts as an insurance against high future prices, i.e. $k<0$ could then be a sensible assumption. For instance,

\footnotetext{
${ }^{15}$ If the auction was not costly, the legislator would be indifferent between choosing forward contracts only, $\Delta_{f}=\frac{\eta}{c}$ and $\Delta_{t}=0$, or choosing $\Delta_{t}=\frac{b_{x}}{x_{M}-x_{L}}$ and $\Delta_{f}=\frac{\eta}{c}-\Delta_{t}$, thus, choosing the former is optimal as claimed in Proposition 3. If transaction costs can be saved, the latter is strictly preferred by the legislator, as discussed in this section.
} 
electricity retailers might want to buy insurance against increasing wholesale prices. This means there is a positive willingness to pay for forward contracts on the wholesale price on energy. A firm that is forced to auction off such contracts may earn a positive premium in the auction, which makes the use of forward contracts more attractive.

\subsection{Regulatory payments that condition on auction proceeds}

The use of forward contract is attractive because it helps to benefit from the information held by financial markets. In principle, this information could be elicited from the financial market more easily in an "information revelation auction". By selling just a few forward contracts, the financial market's information about the state of the world could be inferred from the auction proceeds. Optimal incentive provision could then rely on price contingent transfers whose average level is calibrated by the revealed information from the auction instead of relying on the potentially biased assessment of the regulator.

The drawback of such a mechanism is that it invites manipulation of the auction by the firm. It could easily be profitable to bribe one financial market participant to pay a high price for the contract in the good state of the world (i.e., low baseline probability of high prices), which would then lead the regulation to implement the (high) payments of the bad state of the world. Since in this case the firm would be the only counterparty of a "bribed" financial market participant, the firm can fully compensate the bidder for having overpaid, and keep the profit from the favorable regulation. ${ }^{16}$

Another way of relating the regulation to the auction proceeds is to reduce regulatory transfers in case auction revenues are lower than predicted given the regulator's assessment. This could rule out the incentives of an inefficient network firm to bribe the regulator to suppress information about the type. The network firm could no longer capture the "reimbursement" transfer, if this transfer will only be paid if auction proceeds are as low as predicted.

However, such a mechanism heavily exploits our simplifying assumption that auction proceeds can be higher than predicted only if the regulator has been bribed. Consider the case where there are some transaction cost $k$ in the auction. It might well be the case that $k$ is known only to the financial market (e.g., the degree of market power), while it is stochastic from

\footnotetext{
${ }^{16}$ The effect of bribing financial market participants is fundamentally different here to the case where (only) forward contracts are used. Here, manipulating the auction outcome will trigger transfers paid by the regulator to the firm, which provides the coalition of the firm and the bribed financial market participant with additional funds. If only forward contracts are used, any bribe is a zero sum interaction between the firm and the bribed financial market participant.
} 
the perspective of the legislator, the regulator, and the firm. In that case, it will no longer be possible to identify whether certain (e.g. "too high") realizations of the auction proceeds are due to a mis-announcement of a bribed regulator, or due to a low realization of $k$.

However, in general, having some sort of penalty for the case the auction revenues deviate significantly from what had to be expected from the regulator's announcement might be sensible. This would then further improve the results from using forward contracts, compared to outcome contingent transfers.

\section{Conclusion}

We have analyzed to which extent the use of forward contracts can be beneficial for regulating a network firm providing an essential input. We found that simple forward contracts can solve moral hazard problems of the firm just as good as outcome contingent transfers; their additional benefit rest on the idea that they can better solve the problem of regulatory capture, since financial markets can hardly be bribed to manipulate a regulation in favor of the regulated firm. If in addition to a moral hazard problem also adverse selection problems are present, it remains optimal to use forward contracts only, although the first best can no longer be achieved.

Three basic elements of the underlying problem drive the result that forward contracts can improve regulation: First, there must be a moral hazard problem on the side of the regulated network firm. Second, there must be a significant danger of regulatory capture. Third, the problem of regulatory capture is reduced using a competitive, transaction cost free financial market for the final product. Only where such markets are established, forward contracts have unambiguously positive effects.

All three elements are present in the electricity markets in Europe. Therefore, such forward contract should be considered, at least as a complementary regulatory tool. Whether forward contracts can be applied in other industries depends on whether the three conditions mentioned are met. At least for some markets for natural gas markets, this might be true as well.

\section{References}

Allaz, B., And J.-L. Vila (1993): "Cournot Competition, Forward Markets and Efficiency," Journal of Economic Theory, 59(1), 1-16. 
Borenstein, S., J. Bushnell, and S. Stoft (2000): "The Competitive Effects of Transmission Capacity in a Deregulated Electricity Industry," The RAND Journal of Economics, 31, 294-325.

Bushnell, J. (2007): "Oligopoly Equilibria in Electricity Contract Markets," Journal of Regulatory Economcis, 32, 225-245.

Dal Bó, E. (2006): "Regulatory Capture: A Review," Oxford Review of Economic Policy, $22(2), 203-225$.

de Frutos, M.-A., and N. Fabra (2009): "How to Award Pro-Competitive Forward Contracts. The Case of Electricity Auctions," mimeo, Universidad Carlos III de Madrid.

Fabra, N., And J. Toro (2005): "Price Wars and Collusion in the Spanish Electricity Market," International Journal of Industrial Organization, 23, 155-181.

Faure-Grimaud, A. (2002): "Using Stock Price Information to Regulate Firms," Review of Economic Studies, 69, 169-190.

Fürsch, M., C. Golling, M. Nicolosi, R. Wissen, and D. Lindenberger (2010): "European RES-E Policy Analy," Institute for Energy Economics (ewi), Cologne.

Laffont, J.-J., and J. Tirole (1991): "The Politics of Government Decision-Making: A Theory of Regulatory Capture," Quarterly Journal of Economics, 106(4), 1089-1127.

— (1993): A Theory of Incentives in Procurement and Regulation. MIT Press, Cambridge, MA.

Levine, M. E., And J. L. Forrence (1990): "Regulatory Capture, Public Interest, and the Public Agenda: Toward a Synthesis," Journal of Law, Economics and Organization, 6, $167-198$.

Liski, M., And J.-P. Montero (2006): "Forward trading and collusion in oligopoly," Journal of Economic Theory, 131(1), 212-230.

Loeb, M., And W. A. Magat (1979): "A Decentralized Method for Utility Regulation," Journal of Law and Economics, 22(2), 339-404.

Mahenc, P., and F. Salanie (2004): "Softening Competition Through Forward Contracting," Journal of Economic Theory, 116, 282-293. 
Peltzman, S. (1976): "Toward a More General Theory of Regulation," Journal of Law and Economics, 19(2), 211-240.

Schultz, C. (2009): "Virtual Capacity and Competition," mimeo, University of Copenhagen.

Stigler, G. J. (1971): "The Theory of Economic Regulation," Bell Journal of Economics and Management Science, 2(1), 3-21.

Tirole, J. (1986): "Hierarchies and Bureaucracies: On the Role of Collusion in Organizations," Journal of Law, Economics and Organization, 2(2), 181-214. 